American Journal of Agricultural and Biological Sciences 3 (4): 639-646, 2008

ISSN 1557-4989

(C) 2008 Science Publications

\title{
A Review on Physicochemical and Thermorheological Properties of Sago Starch
}

\author{
A. Mohamed, B. Jamilah, K.A. Abbas, R. Abdul Rahman and K. Roselina \\ Department of Food Technology, Faculty of Food Science and Technology, \\ University Putra Malaysia (UPM), Selangor, Malaysia
}

\begin{abstract}
This study was a part of a research project aiming to investigate the texture characteristics of protein - starch interaction in fish based product keropok lekor. Accordingly, the current review study focused on some physicochemical (molecular weight, viscosity, chemical composition and swelling power) and thermorheological (gelatinization, retrogradation and viscoelsticity) characteristics of sago starch alone and in mixtures with other ingredients such as sucrose, salts and hydroclloids. The inferred outcome of this extensive survey revealed that the gelatinisation temperature for sago-water mixture ranged from $69.4-70.1{ }^{\circ} \mathrm{C}$ which was low compared to sweet potato, tania and yam starches. The role of using hydrocolloids in starch-based foods was to control the rheological properties as well as modifying the texture of the products, enhaning or modifying the gelatinization and retrogradation behaviour and improving water-holding capacity of the system. In the presence of sucrose or sodium chloride, the gelatinisation temperatures of sago starch shifted to higher temperatures and its enthalpy decreased. The addition of salts caused an elevation or depression of gelatinization temperature and gelatinization enthalpy, depending on their types and concentrations used. However, sodium chloride appeared to exhibit a maximum inhibitory effect on starch gelatinisation at a concentration of 6-9\%.
\end{abstract}

Key words: Sago starch, thermorheological properties, gelatinization

\section{INTRODUCTION}

Sago starch (Metroxylon sagu) is produced from the pith of the cycads of the genus, Cycas. Cycas revoluta which is referred to as sago palm, Japanese sago, or king sago and Cycas rumphii as tree sago or queen sago ${ }^{[1]}$.

Sago initially presents in South East Asia and It could be produced from sago palm (Metroxylon spp.), which is also better known as rumbia. It is an important resource especially to the people in rural areas because it has various uses especially in the production of starch either as sago flour or sago pearl.

Sago starch is used in South East Asia in the production of many different kinds of foods such as vermicelli, bread, crackers and biscuits ${ }^{[2]}$. Sago starch mixed with water may be baked to form a product analogous to bread or a pancake. It is used in Sarawak, Malaysia to produce tabaloi, a local biscuit delicacy and bake it starch into traditional product called lempeng which may contains other ingredients such as ground peanuts or other pulses. They are dipped in tea, coffee or other fluids before consumption ${ }^{[3]}$. It is also used as potential source of flour for noodles. However, noodles made from sago starch have limitations due to the absence of gluten and lack of desired functional properties. Sago starch is also used it traditional food such as fish crackers ${ }^{[4]}$ and keropok lekor ${ }^{[5]}$ which are made by mixing the minced fish meat with sago flour, tapioca flour, salt and monosodium glutamate. Keropok lekor is a traditional popular fried snack food in Malaysia which originates from the East coast peninsula Malaysia. The two essential ingredients in keropok lekor are fish and starch which are mixed and the mixture is then moulded into cylinders, steamed, cooled, sliced and sun-dried. Before consumption the slices are fried in hot oil, whereupon the keropok expands into a porous low-density product. Keropok lekor is considered a nutritious snack food due to its high protein composition. It does not resemble any seafood analog due to its high proportion of starch component (30-60\% by weight).

A critical review of this work showed that many researches have focused on starches from corn, wheat and potato and very few reports are available on physicochemical and thermorheological properties of sago starch ${ }^{[6-10]}$, but still no sufficient researches covered theromrheological properties of sago starch

Corresponding Author: K.A. Abbas, Department of Food Technology, Faculty of Food Science and Technology, University Putra Malaysia (UPM), Selangor, Malaysia 
when it used as protein- starch interaction in fish-starch based product such as keropok lekor.

Physicochemical characteristics: Since sago starch is most commonly used as functional ingredient (e.g. thickener, stabilizer, gelling agent) in the food industry, its physicochemical such as gelatinization and retrogradation are most important properties to consider when determining starch uses in food industry applications. The Physicochemical characteristics reported here including molecular weight, viscosity, proximate composition, swelling, gelatinization and retrogradation.

Many researchers have agreed that the molecular weight for amylose ranged between $1.41 \times 10^{6}-2.23 \times 10^{6}$ while for amylopectin the value was from $6.70 \times 10^{6}$ $9.23 \times 10^{6[11,12]}$. It was found that the viscosity for amylose of sago starch ranged from 310 to $460 \mathrm{ml} \mathrm{g}^{-1}$ while for amylopectin under similar conditions the intrinsic viscosity was 210 to $250 \mathrm{~mL} \mathrm{~g}^{-1[13]}$. Compared to this the intrinsic viscosities for amylose obtained from sago starch were higher than those obtained from corn starch but quite similar to potato, 250$570 \mathrm{~mL} \mathrm{~g}^{-1[1]]}$ and cassava, $367 \mathrm{~mL} \mathrm{~g}^{-1[12]}$. Fasihuddin et $a l^{[13]}$ studied the physicochemical characteristics of sago starch and have found that moisture contents of the sago starch ranged between 10.6 and $20.0 \%$ which is typical for commercial starches. Under average ambient temperature and humidity conditions the moisture content of most unmodified starches is around 12\%. All commercial starches either from cereal or tuber sources contain minor or trace quantities of uncombined inorganic materials. The inorganic material normally originates in the crop from which the starch is isolated and also from the water used to process the starch. It was have found that the total amylose contents (lipid free starch) in sago starches ranged between 24\% and $31 \%$ compared to the apparent amylose content (starch with lipid) which was slightly lower and in the range of $24-30 \%$ which was well agreed the published finding values of $22-31.7 \%^{[9,14]}$. Moreover, They found that the amylose obtained from the fractionation procedure based on its iodine binding capacity of $19.5 \%$ while the amylopectin fractions the iodine binding capacity was around $0.3 \%$. Tomoko et al. ${ }^{[15]}$ analyzed sago starch and have found that amylose content of the starch from the lower part of the trunk is higher than that from the upper part of the trunk, which further increases with growth.

Swelling power behaviour of sago starch: In presence of enough water, during heating, the starch granule swells and its volume increases. Tester and Karkalas ${ }^{[16]}$ have expressed that the swelling occurs when starch is heated in presence of water and hydrogen bonds stabilizing the structure of the double helices in crystallites are broken and replaced by hydrogen bonds of water. Karim et al. ${ }^{[2]}$ studied native and alkali-treated sago starch samples and observed that there was a progressive increase in swelling power and solubility with time of alkaline treatment and have found that sago starch treated with $0.5 \% \mathrm{NaOH}$ had a significantly higher swelling power and solubility than those of starch treated with $0.1 \% \mathrm{NaOH}$. Swelling power provide evidence of the magnitude of interaction between starch chains within the amorphous and crystalline domains. Hoover ${ }^{[17]}$ reported that the extent of this interaction is influenced by the amylose/amylopectin ratio and by the characteristics of amylose and amylopectin in terms of molecular weight/distribution, degree and length of branching and conformation. The swelling behaviour of native untreated starch such as sago is primarily a property of the amylopectin content, amylose acts as an inhibitor of swelling, especially in the presence of lipids, when amylose-lipid complex tends to form ${ }^{[18,19]}$. It is suggested that the rigidity of starch granular structure might be proportional to its amylose content and inversely proportional to the degree of granular swelling ${ }^{[20]}$. The presence of sodium chloride affect the swelling power of sago starch. When sodium chloride is added to a starch suspension, it behaved as swelling inhibitor as some protons of alcohol groups in the starch granule become exchanged by sodium ions ${ }^{[21]}$. Lutfor et al. ${ }^{[22]}$ studied the swelling power of sago starch and have found that the maximum swelling was

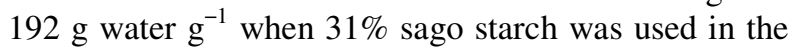
absorbent. The swelling decreased with the increase of sago starch concentration. The equilibrium swelling was reached at $120 \mathrm{~min}$, approximately. The following points present thermorheological behaviour of sago starch as it interact with different ingredients such as water, sucrose, salt and hydrocolloids mined fish.

Gelatinization behaviour of sago starch: When aqueous starch suspensions are heated above the gelatinization temperature, irreversible swelling of the granules occurs along with a concomitant changes of structural order but granules still maintain their identity ${ }^{[23]}$. Sakonidou et al., ${ }^{[24]}$ proposed that these changes included granule swelling due to absorption of moisture in the amorphous regions of the granule, leaching of small molecular weight polymers including amylose, loss of the crystalline order and the consequent loss of birefringence, leaching of larger 
molecular weight polymers from the granule including fragments of amylopectin and, finally, starch solubilization. Several studies have been carried out on the alkali gelatinization of $\operatorname{starch}^{[25-29]}$. Gelatinization onset temperature of starch from the upper part of the trunk is in the range of $65.3-68.2^{\circ} \mathrm{C}$ with a gelatinization conclusion temperature of $75-76^{\circ} \mathrm{C}$. Starch from the lower part of the trunk has a lower gelatinization onset temperature and a higher gelatinization conclusion temperature ${ }^{[15]}$.

Retrogradation of sago starch: Retrogradation of starch is one of the main causes of food-quality deterioration ${ }^{[30]}$. In starch-based food, prevention of starch retrogradation is one of the most important aspect in controlling the quality of such foods. Processing of starch - based products normally causes starch gelatinization, i.e. irreversible swelling or even disruption of the starch granules which result in amylose leaching into the solution depending on the severity of the treatment applied. Heat-gelatinized starch, however, loses gradually the properties depending on the storage time and temperature. This event is recognized as retrogradation. Which has been often treated as a typical effective factor on shelf-life acceptability $^{[31]}$ and quality $\operatorname{loss}^{[30,32,33]}$ of starchcontaining foods. In the presence of $\mathrm{Na}_{2} \mathrm{CO}_{3}$ and $\mathrm{NaOH}$, the aged starch retrogradation was retarded ${ }^{[34]}$. Sago starch treated with $0.5 \% \mathrm{NaOH}$ for 30 days has the lowest $\Delta 8 \mathrm{H}_{\mathrm{R}}$ values ${ }^{[35]}$ which indicates that higher concentration and longer duration of alkali treatment on starch inhibit retrogradation.

Thermal behaviour of sago starch - water mixture: It was reported that high water contents, the amorphous regions of the granules imbibed water and swelled, resulting in stripping or separation of starch chains from portions of these crystallites ${ }^{[36]}$. When all crystals are stripped at high moisture levels, there would not be any crystallites remaining to be melted at those levels. The granules containing least stable crystallites start to change first upon heating. Water absorption by the granules lowers the melting points of crystallites, which results in quick melting of remaining crystallites. This process reduces the constraints of still remaining crystallites to lower their melting points. This cooperative process happens quickly when there was sufficient water and gave a narrow or single DSC endotherm. At low water contents, however, there is not sufficient water for cooperative melting to take place. This results in a second endotherm (or a shoulder depending on the water content), which represents crystallites melting after the cooperative process, at a higher temperature ${ }^{[37]}$. Hongsheng et al. ${ }^{[38]}$ studied the gelatinization behaviours of cornstarch with different amylose/amylopectin contents with DSC, using a stainless steel high-pressure pan, as a function of water content $(9-75 \%)$ and temperature $\left(0-200^{\circ} \mathrm{C}\right)$. He concluded that the number of endotherms and the enthalpy of gelatinization depend on the amylose/amylopectin, moisture and lipid content. Up to five endotherms and one exotherm were detected for corn maize starch when the water content is about $50 \%$.

Some researchers ${ }^{[39,40]}$ studied the thermal behaviour of sago starch using DSC and the results show that the gelatinisation temperature for sago starches ranged from $69.4-70.1^{\circ} \mathrm{C}$ and it gelatinisation temperature for sago starches are high compared to corn, pea and potato but low compared to starch from sweet potato, tania and yam.. DSC is an extremely valuable tool to qualify the gelatinization of starch and has been used to study the thermal behaviour of starches ${ }^{[41-43]}$. DSC thermograms give the possibility of analyzing transition temperatures as well as transition enthalpies. The enthalpy $(\Delta \mathrm{H})$ of a transition was interpreted as corresponding to the amount of crystal order (or double-helical structure) in the starch suspensions that disrupted at heating scans.

Thermal behaviour of sago starch-hydrocolloids mixture: Hydrocolloids are widely used in the food industry as thickening water-holding and stabilizing agents and texture modifiers. It is generally assumed that this type of hydrocolloid functions by modifying the rheological properties of the aqueous phase between the dispersed particles or droplets ${ }^{[44]}$. It has been widely known in the food industry that hydrocolloids, especially native and modified polysaccharides, exhibit many functions, e.g., to control rheological and textural properties of foods, to improve moisture retention and to maintain overall product quality during storage ${ }^{[45]}$. Sittikijyothin et al. ${ }^{[46]}$ reported that the great advantages of hydrocolloids are their ability, at relatively low concentrations, to form very viscous solutions that are only slightly affected by $\mathrm{pH}$, added ions and/or heat processing. The rheological behavior of hydrocolloids is of special importance when they are used to modify textural attributes ${ }^{[47]}$. Many investigations have tried to clarify the role and potential usefulness of hydrocolloids such as locust bean gum and guar gum in controlling rheology and modifying the texture of starch-based food products ${ }^{[48-52]}$. They concluded that the addition of hydrocolloids enhance or modify the gelatinization and retrogradation behaviour of starch. The functions of adding hydrocolloid to starch, including the inhibition of retrogradation or the 
improvement of water-holding capacity for the starch system vary depending on the macromolecular characteristics of hydrocolloid phase behavior, which could dominate the composite properties of starch/hydrocolloid system, is affected greatly not only by the mixing ratio but also by the molecular weight of each component ${ }^{[53,54]}$.

Thermal behaviour of sago starch-sugar mixture: Starch gelatinization in the presence of sugars has been described as a mechanical relaxation process affected by the mobility of aqueous sugar solutions. Ahmed and Williams ${ }^{[55]}$ studied the gelatinizatiion of sago starch using DSC technique and found that the gelatinisation temperature increased and the swelling of starch granules decreases in the presence of sugars. As it reported earlier, sucrose is commonly was found to have a greater effect on the temperature of gelatinization than other disaccharides ${ }^{[56]}$. It is well known that, generally, monosaccharides delay gelatinisation less than disaccharides, except maltose, which acts like monosaccharides. Spies, ${ }^{[57]}$ have observed that the addition of sucrose, which dissolves in the water, has the functional effect of increasing solvent volume, which can be exerted this effect to different extents when compared on a molar basis. In systems studied by Maruff et al. ${ }^{[21]}$, it was found that in excess water, sucrose causes an increase in To, Tp and Tm while $\Delta \mathrm{T}\left(\mathrm{T}_{\mathrm{m}}-\mathrm{T}_{\mathrm{o}}\right)$ is more or less unaffected. The same authors observed that when increasing levels of sucrose (0-1.7 g sucrose/g starch) were added to sago starch at water: starch ratio of 3:1, To, Tp and Tm were all increased and $\Delta \mathrm{H}$ for samples of ratios from 0.0$0.6 \mathrm{~g} \mathrm{sucrose} / \mathrm{g}$ starch remained unchanged while at water: starch ratios of 10:1 to 2:1 the effect on the DSC endotherm of adding sucrose is an increase of the gelatinisation temperature. It was also found that sucrose delays the start of the gelatinisation process. For example, from 0.0-0.2 g sucrose/g starch the delay of gelatinisation temperature ranged between 2.1 and $3.4^{\circ} \mathrm{C}$ at water:starch ratio $3: 1$ and $1: 1 . \mathrm{T}_{\mathrm{o}}, \mathrm{T}_{\mathrm{p}}$ and $\mathrm{T}_{\mathrm{m}}$ as a function of the sucrose to starch ratio. $\Delta \mathrm{H}$ was $5.37 \pm 0.27 \mathrm{~J} \mathrm{~g}^{-1}$ starch without added sucrose and $4.30 \pm 0.12 \mathrm{~J} \mathrm{~g}^{-1}$ starch at the sucrose to starch ratio 1.7:1. These findings were well agreed with that reported by Eliasson ${ }^{[58]}$ which observed that $T_{o}$ increased from about $58.3^{\circ} \mathrm{C}$ for potato starch at a water to starch ratio of $3: 1$ to about $72.1^{\circ} \mathrm{C}$ at a sucrose to starch ratio of $1.7: 1$.

Thermal behaviour of sago starch-salts mixture: Many studies have been curried out to investigate the effect of salts when it mixed with $\operatorname{starch}^{[7,21,59-64]}$ which reported that salts caused an elevation or depression of gelatinization temperature and gelatinization enthalpy, depending on the types of salt and their concentrations used. Researchers ${ }^{[7,21,59]}$ have reported that $\mathrm{NaCl}$ and $\mathrm{CaCl}_{2}$ combination at low concentrations, slightly increased the $T_{p}$ of sago starch but, when the concentrations increased further (up to $\sim 2 \mathrm{M}$ for $\mathrm{NaCl}$ and $\sim 1 \mathrm{M}$ for $\mathrm{CaCl}_{2}$ ), these temperatures decreased. The effects of salts on thermal and rheological properties of starch highly depend on the type of salt as well as on the concentration ${ }^{[58]}$. Sodium chloride $(\mathrm{NaCl})$ had a different effect on starch gelatinisation. Bello and Paredes $^{[65]}$ have studied the effect of adding sodium chloride and have found that when sodium chloride concentration increased, the enthalpy value decreased. However, sodium chloride appeared to exhibit a maximum inhibitory effect on starch gelatinisation at a concentration of $6-9 \%{ }^{[66]}$. The researchers explained that the decrease in enthalpy when salt was added could arise from the influence of sodium and chloride ions on water, starch and their interactions. When they examined samples under polarised light, the loss of birefringence in the samples was delayed as a result of addition of sodium chloride. According to Cheow et $a l^{[67]}$, salts has the great effect of on the increase of gelatinization temperature of starch in fish starch mixture compared to sugar and MSG. They also reported that the temperature range of gelatinization decreases with increase in fish content.

Rheological behaviour of sago starh: Rheology is defined as the study of deformation and flow of matter. Deformation pertains to matter which is solid and flow to matter which is liquid ${ }^{[68]}$. In the simple case, the rheological properties of interest in solids is their elasticity and in liquid is their viscosity. Food is more complex and are neither viscous nor elastic but are viscoelastic $^{[69,70]}$. The rheological response of any material is physically expressed as functions of either strain and strain rate or strain time. There are two types of stresses: those that act in a direction parallel to the material surface they deform, called shear stress and those that acts in a direction perpendicular to surface of material they deform, called normal stresses. It is well recognized that rheological properties play a role in process design, evaluation and modeling. Rheological data are required for calculation in any food process such as pasteurization, evaporation, drying and aseptic processing. Rheological properties of starch paste and gels and other functional properties vary with species and variants ${ }^{[71,72]}$. One of the most important features of starch in food systems is its ability to give structure by the formation of a gel ${ }^{[73]}$. Dynamic viscoelastic 
methods can provide an excellent tool for studying rheological changes during heating and cooling without breaking the stucrure ${ }^{[74]}$. Many studies have reported the (amylographic) viscosity of sago $\operatorname{starch}^{[75-78]}$ and relatively few have applied any rheological model to the shear stress-shear rate or viscosity-speed behaviour of the $\operatorname{starch}^{[14,79]}$. The rheological behaviour of six sample of sago starch of $4 \%(\mathrm{w} / \mathrm{w})$ paste were studied at $30^{\circ} \mathrm{C}, 40^{\circ} \mathrm{C}, 50^{\circ} \mathrm{C}, 60^{\circ} \mathrm{C}$ and $70^{\circ} \mathrm{C}$ and it was found that the rheological and viscosity of were inversely related to the temperature and they showed different temperature sensitivity but their granules are essentially identical in size and configuration ${ }^{[80]}$. Still there is a lack in the Literature regarding the rheological behaviour of sago starch protein- starch mixture. Kyaw et al. ${ }^{[5]}$ used sago starch with fish to starch ratio of $0: 100,10: 90,15: 85,30: 70$ and 50:50, respectively with added water in the percentage of $0,10,15,20,30$, 50 and $70 \%$ and found that an increase in the viscoelstisity of the product was corresponded to the ratio of fish to starch added $(\mathrm{F} / \mathrm{S})$.

optimized ingredients used in Keropok lekor processing and they concluded that rheologically, the gel characteristic of Keropok lekor varies with proportion of fish and sago starch used. And concluded that the best formulation of Keropok lekor was $60 \%$ fish and $30 \%$ sago starch, $10 \%$ tapioca starch with $25 \%$ water, 3.8 sugar, $2.5 \%$ salt and $0.1 \%$ monosodium glutamate based on total weight of fish and starch mixture.

Usage of sago starch in some food production: Heat moisture treatment is a promising technique for improving the quality of sago noodle and is performed by exposing the starch to high temperatures $\left(110^{\circ} \mathrm{C}\right.$, $16 \mathrm{~h})$ at a moisture content of $25 \%{ }^{[81]}$. Cross-linked sago starch can be used for the partial substitution of wheat flour in the production of alkaline noodles. Instant noodles which have low levels $(0.1-0.3 \%)$ of alkaline salts added as a texture improver are not classified as alkaline noodles because they lack the strong alkaline flavor and color associated with the addition of high levels $(0.5-1.5 \%)$ of alkaline salts ${ }^{[22]}$. Clarke et al. ${ }^{[83]}$ reported production of white bread, which is consumed and rapidly rising in Indonesia is made of sago starch which can participate in percentage up $40 \%$ of the content of the white bread. However, Singhal et $a l^{[84]}$ have reported that In Sarawak, Malaysia, sago starch is widely used to produce 'tabaloi', which is a kind of local biscuit delicacy as well as baking it into another traditional food called lempengs. The lempengs are usually made entirely of starch, but they may occasionally contain other ingredients such as ground peanuts or other pulses. On the other hand, sago starch was also used in production of keropok, a Malaysian fish- starch snack food ${ }^{[4]}$. The crispness which can be achieved using starch, is the most important parameter governing the quality of $\operatorname{keropok}^{[85]}$.

\section{CONCLUSION}

Sago starch has high swelling power and low gelatinization temperature. when it is heated in water mixture with addition of salts, or sucrose or hydrocolloids, an increament in the gelatinization temperature has been noticed. Alkali treatment at higher concentration and longer duration effectively inhibited retrogradation of this starch. This review research revealed that the physicochemical as well as the thermoreheological properties of sago starch presented make it to be considered as an excellent starch resource with possible applications in many food processing.

\section{REFERENCES}

1. Karim, A.A. Tie, A.P., Manan, D.M.A and Zaidul, I.S.M. 2008. Starch from the sago (Metroxylon sagu) Palm Tree - Properties, Prospects, and Challenges as a New Industrial Source for Food and Other Uses. Journal of Comperehensive Reviews in Food Science and Food Safety 7: 215228.

2. Karim, A.A., M.Z. Nadiha, F.K. Chen, Y.P. Phuah, Y.M. Chui and A. Fazilah, 2008. Pasting and retrogradation properties of alkali-treated sago (Metroxylon sagu) starch. J Food Hydrocolloids, 22: 1044-1053.

3. Rekha, S., F. John, M. Sajilata, Gopalakrishnan,, J. Charles and F. Putri, 2008. Industrial production, processing and utilization of sago pa a $1 \mathrm{~m}$-derived products. J. Carbohydrate Polymers, 72: 1-2.

4. Kyaw, Z.Y., S.Y. Yu, C.S. Cheow and M.H. Dzulkifly, 1999. The effect of steaming time on linear expansion of fish crackers (keropok). J. Sci. Food Agric., 79: 1340-1344.

5. Kyaw, Z.Y., Yu, S.Y., Cheow, C.S., Dzulkifly, M and Howell, N. K. 2001. Effect of fish to starch ratio on viscoelastic properties and microstructure of fish craker ('keropok') dough. International Journal of Food Science and Technology.

6. Ahmad, F.B., P.A Williams, J.L. Doublier, S. Durand and A. Buleon, 1999. Physico-chemical characterisation of sago starch. Carbohydrate Polymers, 38: 361-370.

7. Ahmad, F.B. and P.A Williams, 1999. Effect of salts on the gelatinization and rheological properties of sago starch. J. Agric. Food Chem., 47: 3359-3366. 
8. Arai, Y., T. Kaneko and T. Ito, 1981. Rheological and chemical properties of sago starch. Jap. J. Trop. Agic., 25: 41-46.

9. Kawabata, A., S. Sawayama, N. Nagashima, R.R. Rosario and M. Nakamura, 1984. Some physicochemical properties of tropical starches. J. Jap. Soc. Starch Sci., 31: 224-232.

10. Sim, S.L., C.G. Oates and H.A. Wong, 1991. Characterisation and comparison of sago starches obtained from metroxylon sagu processed at different times. J. Starch, 43: 459-466.

11. Colonna, P. and C. Mercier, 1984. Macromolecular structure of wrinkled-and smooth- pea starch components. J. Carbohydrate Res., 126: 233-237.

12. Roger, P. and P. Colonna, 1993. Evidence of the presence of large aggregates contaminating amylose solutions. Carbohydrate Polymer, 21: 83-89.

13. Fasihuddin, B., Ahmad, A. Peter, Williams, Jean-Louis Doublier, Sylvie Durand and Alain Buleon, 1999. Physico-chemical characterisation of sago starch. J. Carbohydrate Polymers, 38: 361-370.

14. Sim, S.L., C.G. Oates and H.A. Wang, 1991. Studies on sago starch. Part I. characterisation and comparison of sago starches obtained from metroxylon sagu processed at different times. Starch Starke, 43: 459-466.

15. Tomoko, H., H. Tamao, J.F. Shoon, K. Keiji and T. Setsuko, 2000. Physicochemical properties of starches obtained from various parts of sago palm trunks at different growth stages (Part 2). The relative crystallinity, structure and gelatinization properties of sago starches at different growth stages. J. Applied Glycosci., 47: 335-341.

16. Tester, R.F. and J. Karkalas, 1996. Swelling and gelatinization of oat starches. J. Cereal Chem., 73: 271-273.

17. Hoover, R., 2001. Composition, molecular structure, and physicochemical properties of tuber and root starches: A review. Carbohydrate Polymers, 45: 253-267.

18. Sandhya, M.R. and K.R. Bhattacharya, 1989. Rheology of rice flour pastes: Effects of variety, concentration and temperature and time of cooking. J. Texture Stud., 20: 127-137.

19. Tester, R.F. and W.R. Morrison, 1990. Swelling and gelatinization of cereal starch I. Effects of amylopectin, amylose and lipids. J. Cereal Chem., 67: 551-557.

20. Lii, C.Y., M.L. Tsai and K.H. Tseng, 1996. Effect of amylose content and the rheological properties of rice starch. J. Cereal Chem., 73: 415-420.

21. Maaurf, A.G., Y.B. Che Man, B.A. Asbi, A.H. Junainah and J.F. Kennedy, 2001. Gelatinisation of sago starch in the presence of sucrose and sodium chloride as assessed by differential scanning calorimetry. J. Carbohydrate Polymers, 45: 335-345.
22. Lutfor, M.R., S. Sidik, W.M.Z. Wan Yunus , M.Z. Ab Rahman, A. Mansoor and H. Jelas, 2001. Preparation and swelling of polymeric absorbent containing hydroxamic acid group from polymer grafted sago starch. J. Carbohydrate Polymers, 45: 95-100.

23. Hug-Iten, S., F. Esher and B. Conde-Petit, 2001. Structural properties of Starch in bread and bread model systems influence of an antistaling-amylase. J. Cereal Chem., 78: 421-428.

24. Sakonidou, E.P., T.D. Karapantsios and S.N. Raphaelides, 2003. Mass transfer limitations during starch gelatinization. J. Carbohydrate Polymers, 53: 53-59.

25. Lai, L.N., A.A. Karim, M.H. Norziah and C.C. Seow. 2002. Effects of $\mathrm{Na}_{2} \mathrm{CO}_{3}$ and $\mathrm{NaOH}$ on DSC thermal profiles of selected native cereal starches. J. Food Chem., 78: 355-362.

26. Mondragón, M., L.A. Bello-Pérez, E. Agama, A. Melo, D. Betancur-Ancona and J.L. Peña, 2004. Effect of nixtamalization on the modification of the crystalline structure of maize starch. J. Carbohydrate Polymers, 55: 411-418.

27. Ragheb, A.A., I.A. El-Thalouth and S. Tawfik, 1995. Gelatinization of starch in aqueous alkaline solutions. J. Starch Stärke, 47: 338-345.

28. Roberts, S.A. and K.E. Cameron, 2002. The effects of concentration and sodium hydroxide on the rheological properties of potato starch gelatinization. Carbohydrate Polymers, 50: 133.143

29. Wootton, M. and P. Ho, 1989. Alkali gelatinization of wheat starch. J. Starch Stärke, 41: 261-265.

30. Karim, A.A., M.H. Norziah and C.C. Seow, 2000. Methods for the study of starch retrogradation. J. Food Chem., 71: 9-36.

31. Biliaderis, C.G. and J. Zawistowski, 1990. Viscoelastic behaviour of aging starch gels: Effects of concentration, temperature and starch hydrolysates on network properties. J. Cereal Chem., 67: 240-246.

32. Bauer, B.A., T. Wiehle and D. Knorr, 2005. Impact of high hydrostatic pressure treatment on the resistant starch content of wheat starch. J. Starch Stärke, 57: 124-133.

33. Chung, H., H.S. Lim and S. Lim, 2006. Effect of partial gelatinization and retrogradation on the enzymatic digestion of waxy rice starch. J. Cereal Sci. press, 43: 353-359.

34. Lai, L.N., A.A. Karim, M.H. Norziah and. C.C. Seow, 2004. Effects of $\mathrm{Na}_{2} \mathrm{CO}_{3}$ and $\mathrm{NaOH}$ on pasting properties of selected native cereal starches. J. Food Sci., 69: 249-256.

35. Karim, A.A., M.Z. Nadiha, F.K. Chen, Y.P. Phuah, Y.M. Chui and A. Fazilah, 2006. Pasting and retrogradation properties of alkali-treated sago (Metroxylon sagu) starch. J. Food Hydrocolloids, 22: 1044-1053. 
36. Donovan, J.W., 1979. Phase transitions of the starch-water system. J. Biopolymers, 18: 263-275.

37. Evans, I.D. and D.R. Haisman, 1982. The effect of solutes on the gelatinization temperature range of potato starch. J. Starch Stärke, 34: 224-231.

38. Hongsheng, L., Y. Long, X. Fengwei and C. Ling, 2006. Gelatinization of cornstarch with different amylase amylopectin content. J. Carbohydrate Polymer, 65: 357-363.

39. Tian, S.J., J.E. Rickard and J.M.W. Blanshard, 1991. Physicochemical properties of sweet potato starch. J. Sci. Food Agric., 57: 459-491.

40. Veletudie, J.C., L. Guadeloupe, P. Colonna, B. Bouchet and D.J. Gallant, 1995. Gelatinisation of sweet potato, tania and yam tuber starches. J. Starch, 47: 289-306.

41. Tananuwong, K. and D.S. Reid, 2004. DSC and NMR relaxation studies of starch-water interactions during gelatinization. J. Carbohydrate Polymers, 58: 345-358.

42. Tufvesson, F., M. Wahlgren and A.C. Eliasson, 2003. Formation of amylose-lipid complexes and effects of temperatue treatment. J. Starch Stärke, 55: 61-71.

43. Yu, L. and G. Christie, 2001. Measurement of starch thermal transition using differential scanning calorimetry. J. Carbohydrate Polymer, 46: 179-184.

44. Dickinson, E., 2003. Hydrocolloids at interfaces and the influence on the properties dispersed systems. J. Hydrocolloids, 17: 25-39.

45. Funami, T., Y. Kataoka, T. Omoto, Y. Goto, I. Asai and K. Nishinari, 2005. Effects of non-ionic polysaccharides on the gelatinization and retrogradation behavior of wheat starch. J. Food Hydrocolloids, 19: 1-13.

46. Sittikijyothin, W., D. Torres and M.P. Goncalves, 2005. Modelling the rheological behaviour of galactomannan aqueous solutions. J. Carbohydrate Polymers, 59: 339-350.

47. Da Silva, J.A.L., M.S. Pedro, J.C. Oliveira and M.A. Rao, 1997. Granule size distribution and rheological behavior of heated modified waxy and unmodified maize starch dispersions. J. Texture Stud., 28: 123-138.

48. Funami, T., Y. Kataoka, T. Omoto, Y. Goto, I. Asai and K. Nishinari, 2005 Food hydrocolloids control the gelatinization and retrogradation behavior of starch. 2b. Functions of guar gums with different molecular weights on the retrogradation behavior of corn starch. J. Food Hydrocolloids, 19: 25-36.
49. Funami, T., Y. Kataoka, T. Omoto, Y. Goto, I. Asai and K. Nishinari, 2005. Food hydrocolloids control the gelatinization and retrogradation behavior of starch. 2a. Functions of guar gums with different molecular weights on the gelatinization behavior of corn starch. J. Food Hydrocolloids, 19: $15-24$.

50. Kulicke, W.M., D. Eidam, F. Kath, M. Kix and A.H. Kull, 1996. Hydrocolloids and rheology: Regulation of visco-elastic characteristics of waxy rice starch in mixture with galactomannans. J. Starch Stärke, 48: 105-114.

51. Rayment, P., S.B. Ross-Murphy and P.R. Ellis, 1995. Rheological properties of guar galactomannan and rice starch mixtures. I. Steady shear measurements. J. Carbohydrate Polymers, 28: 121-130.

52. Sudhakar, V., R.S. Singhal and P.R. Kulkarni, 1996. Starch-galactomannan interactions: Functionality and rheological aspects. J. Food Chem., 55: 259-264.

53. Annable, P., M.G. Fitton, B. Harris, G.O. Phillips and P.A. Williams, 1994. Phase behavior and rheology of mixed polymer systems containing starch. J. Food Hydrocolloids, 8: 351-359.

54. Closs, C.B., B. Conde-Petit, I.D. Roberts, V.B. Tolstoguzov and F. Escher, 1999. Phase separation and rheology of aqueous starch galactomannan systems. J. Carbohydrate Polymers, 39: 67-77.

55. Ahmad, F.B. and P.A. Williams, 1999. Effect of sugars on the thermal and rheological properties of sago starch. J. Biopolymers, 50: 401-412.

56. Savage, H.L. and E.M. Osman, 1978. Effect of certain sugars and sugar alcohols on the swelling on corn starch granules. J. Cereal Chem., 55: 447-454.

57. Spies, R.D. and R.C. Hoseney, 1982. Effect of sugar on starch retrogradation. J. Cereal Chem., 59: $128-129$.

58. Eliasson, A.C. and M. Gudmundsson, 2006. Starch: Physicochemical and Functional Aspects. In: Carbohydrates in Food, Eliasson, A.C. (Ed.). CRC Press, Boca Raton, FL, pp: 391-469.

59. Ahmad, F.B. and P.A. Williams, 2002. Gelatinisation Properties of Sago Starch in the Presence of Salts. In: Gums and Stabilisers for the Food Industry Vol. 11, Williams, P.A. and G.O. Phillips (Eds.). The Royal Society of Chemistry, Cambridge, UK, pp: 145-157.

60. Chungcharoen, A. and D.B. Lund, 1987. Influence of solutes and water on rice starch gelatinization. J. Cereal Chem., 64: 240-243. 
61. Jane, J.L., 1993. Mechanism of starch gelatinization in neutral salt solutions. J. Od Starch Stärke, 45: 161-166.

62. Jyothi, A.N., K. Sasikiran, M.S. Sajeev, R. Revamma and S.N. Moorthy, 2005. Gelatinisation properties of cassava starch in the presence of salts, acids and oxidising agents. J. Starch Stärke, 57: 547-555.

63. Oosten, B.J., 1982. Tentative hypothesis to explain how electrolytes affect the gelatinization temperature of starches in water. J. Starch Stärke, 34: 233-239.

64. Oosten, B.J., 1983. Explanations for phenomena arising from starch-electrolytes interactions. J. Starch Stärke, 35: 166-169.

65. Bello-Perez, L.A. and O., Paredes-Lopez, 1995. Starch and amylopectin: Effect of solutes on their calorimetric behavior. J. Food Chem., 53: 243 247.

66. Wootton, M. and A. Bamunuarachchi, 1980. Application of differential scanning calorimetry to starch gelatinisation. 111. Effect of sucrose and sodium chloride. J. Starch Staerke, 32:126-129.

67. Cheow, C.S., S.Y. Yu and K.H. Nazlin, 1999. Effect of salt, sugar and monosodium glutamate on the viscoelastic properties of fish craker (keropok). J. Food Process. Prev., 23: 21-37.

68. Rao, M.A., 1999. Introduction. In: Rheology of Fluid and Semisolid Foods Principles and Applications, Rao, M.A. (Ed.). Aspen Publishers, Gaithersburg, pp: 21-24.

69. Oakenfull, D., 1987. Gelling agents. J. Crit. Rev. Food sci. Nutr., 26: 1-225.

70. Rajendra, P.B., 1992. Food texture and rheology: A tutorial review. J. Food Eng., 16: 1-6.

71. Kim, S.Y., D.P. Wiesenborn, P.H. Orr and L.A Grant, 1995. Screening potato starch for novel properties using differential scanning calorimetry. J. Food Sci., 60: 1060-1065.

72. Lai, H.M., 2001. Effects of hydrothermal treatment on the physico-chemical properties of pregelatinized rice flour. J. Food Chem., 72: 455-463.

73. Aguilera, J.M and E. Rojas, 1996. Rheological, thermal and microstructure of whey proteincassava satarch gel. J. Food Sci., 61: 961-966.
74. Autio, K., 1990. Rheological and Microstructural changes of oat barley starches during heating and cooling. J. Food Struct., 9: 297-304

75. Ito, T., Y. Arai and T. Kaneko, 1986. Rheological properties of sago starch and the formation of hexane from mannitol for utilisation of sago starch. In: Proceedings of the 3rd International Sago Symposium, The Sago Palm Research Fund, Tokyo, May 1986. pp: 153-160.

76. Takahashi, S., 1986. Some useful properties of sago starch in cookery science. In: Proceedings of the 3rd International Sago Symposium, Yamada, The Sago Palm Research Fund, Tokyo, May 1986. pp: 208-216.

77. Takeda, Y., C. Takeda, A. Suzuki and S. Hizukuri, 1989. Structures and properties of sago starches with low and high viscosities on amylography. J. Food Sci., 54: 177-182.

78. Khatijah, I. and H. Patimah, 1998. Physicochemical properties of local native starches. J. Trop. Agric. Food Sci., 26: 990-104.

79. Nurul, M.I., M.B.M.N. Azemi and D.M.A. Manan, 1999. Rheological behaviour of sago (Metroxylon sagu) starch paste. J. Food Chem., 64: 501-505.

80. Sopade, P.A. and K. Kiaka, 2001. Rheology and microstructure of sago starch from Papua New Guinea. J. Food Eng., 50: 47-57.

81. Purwani, E.Y., R. Thahir and K. Muslich, 2006. Effect of heat moisture treatment of sago starch on its noodle quality. Indonesian J. Agric. Sci., 7: 8-14.

82. http://www.aaccnet.org/.

83. Clarke, P.A., P.A.E.S. Sim and D. Tan, The use of sago flour in bread making. J. Trop. Sci., 22: 189-195.

84. Singhal,S.R., Kennedy, F.J., Gopalakrishnan, M.S., Charles J. Knill, J.C. and Akmar, F.P. Industrial production, processing, and utilization of sago palm-derived products. Journal of Carbohydrate Polymers 72: 1-20.

85. Siaw, C.L., A.Z. Idrus and S.Y. Yu, 1985. Intermediate technology for fish cracker (keropok) production. J. Food Technol., 20: 17-21. 